\title{
Controlled randomised trial of visual biofeedback versus muscle training without a visual display for intractable constipation
}

\author{
D Koutsomanis, J E Lennard-Jones, A J Roy, M A Kamm
}

\begin{abstract}
Training to contract the abdominal muscles effectively and to relax the pelvic floor during defecation straining helps some patients with severe constipation. Hitherto all such training has used a visible or audible signal of sphincter muscle activity as a biofeedback method to assist in relaxation. A randomised controlled trial comparing the outcome of muscular training without any biofeedback device with the same training supplemented by an electromyographic (EMG) record visible to the patient is reported. Significant symptomatic improvement was noted and electromyographic measurements confirmed a decrease in pelvic floor muscle activity during defecation straining after treatment in both groups. The outcome was similar in the two treatment groups. Muscular coordination training using personal instruction and encouragement without a visual display is thus a potentially successful treatment suitable for outpatient use by paramedical personnel. (Gut 1995; 37: 95-99)
\end{abstract}

Service de Medecine C, CHG de Fécamp, 76400 Fécamp, France D Koutsomanis

St Mark's Hospital, London EC1V 2PS

J E Lennard-Jones

A J Roy

M A Kamm

Correspondence to: Professor J E Lennard-Jones, St Mark's Hospital, City Road, London ECIV 2PS.

Accepted for publication 1 November 1994

Keywords: constipation, muscular coordination training, biofeedback, electromyography.

Two types of muscular incoordination may affect the ability to defecate - some patients contract rather than relax the muscles around the anal canal, others are unable to generate propulsive force in the pelvis. ${ }^{1}$ Biofeedback designed to help patients relax the pelvic floor benefits some of these patients. All techniques reported thus far have used some measuring

TABLE I Comparability of the initial treatment groups

\begin{tabular}{lll}
\hline Characteristics & BF group & MCT group \\
\hline No & 30 & 30 \\
Age (y) (mean (range)) & $40(20-64)$ & $41(23-63)$ \\
Sex & $24 \mathrm{f}$ & $29 \mathrm{f}$ \\
Length of history (y) (mean (range)) & $14(1-40)$ & $13(3-40)$ \\
Bowel frequency (/wk): & 7 & 8 \\
$<2$ & 12 & 10 \\
$3-7$ & 11 & 12 \\
$>7$ & 7 & 9 \\
Episodes of straining (/wk): & 16 & 16 \\
$<3$ & 7 & 5 \\
$3-7$ & 13 & 18 \\
$>7$ & 14 & 18 \\
No of patients who digitated & 7 & 10 \\
No of patients who used laxatives & 12 & 13 \\
No of patients with slow transit (>4 markers at $120 \mathrm{~h}$ ) & \\
No of patients who were unable to expel a water filled balloon & 22 & 25 \\
No of patients who had an increase of EMG activity during & 1 & 0 \\
defecation straining & &
\end{tabular}

$\mathrm{BF}=$ biofeedback; $\mathrm{MCT}=$ muscular coordination training; $\mathrm{EMG}=$ electromyographic. device which enables the patient to know whether or not the pelvic floor muscles contract on defecation straining.

Controlled study is now needed to simplify muscular training to its essential elements. This paper describes the first randomised controlled trial to show if the visual biofeedback component is necessary to help the patient learn pelvic floor muscular relaxation. If, as our results suggest, muscular training without any measuring equipment relieves the symptoms of many patients, then this safe, effective, and long lasting treatment is applicable as an outpatient technique which can be undertaken by paramedical personnel.

\section{Patients and methods}

\section{SELECTION OF PATIENTS}

We studied a consecutive series of 60 adult patients, referred to the physiological laboratory for biofeedback treatment: all complained of a bowel frequency of less than three stools weekly or excessive straining on defecation, or both. None was responsive to standard treatments with a high fibre diet and laxatives, and the symptoms were severe enough for referral to a specialist hospital. There were no exclusion criteria on grounds of age or other personal factors. Patients with structural disease of the rectum or colon, as judged by barium enema, defecating proctography, or absence of the rectoanal distension reflex were not included. Most patients showed evidence of pelvic incoordination judged by an increase in pelvic floor muscular activity, determined by electromyographic (EMG) measurements or by the inability to expel a water filled balloon from the rectum on defecation straining (Table I), but those who complained of severe constipation were treated consecutively and these criteria were not required as essential for entry into the trial.

CONDUCT OF THE TRIAL

The basis of muscular coordination training was explained to each patient. If this treatment was accepted, it was further explained that the need for a visual display of muscular activity is uncertain and the patient was asked to accept initial randomisation into a group treated with or without the display. Each patient was assured that if the first treatment used was unsuccessful after at least two sessions, the alternative treatment would be offered. Before treatment, and after completion of one or both 
treatments, the patient was asked to complete a diary card of bowel symptoms and to accept a number of physiological measurements as described elsewhere. ${ }^{1}$.

If the patient gave signed consent to enter the trial, randomisation using a consecutive set of random numbers in sealed envelopes was performed.

If the first treatment given was judged unsuccessful by both patient and doctor after two training sessions, the alternative treatment was given. The diary card and repeat physiological measurements were repeated immediately after the last treatment given. Symptomatic follow up by diary card was repeated twice during the two to three months after ending treatment. The patient was not seen between the end of treatment and the follow up assessments.

ASSESSMENT OF SYMPTOMS BY DIARY CARD On each of seven consecutive days the patient recorded the number of bowel actions and stool consistency; the number of straining episodes and total time spent straining each day; the need for digitation; use of laxatives, suppositories, or enemas; episodes of abdominal pain and their duration; and an overall assessment of symptoms as better, the same, or worse than usual

\section{PHYSIOLOGICAL ASSESSMENT}

\section{Whole gut transit rate}

An abdominal radiograph was performed 120 hours after taking radio-opaque markers. For this study, retention of more than $20 \%$ of the markers at 120 hours was regarded as abnormal. ${ }^{2}$

\section{Electromyography}

Two adhesive EMG electrodes were placed on the skin over the external anal sphincter at the anal margin. The mean amplitudes $(\mu \mathrm{V})$ of the resting trace, the increased activity on maximal voluntary contraction of the anal canal, and the amplitude during straining in an attempt to evacuate a $50 \mathrm{ml}$ air filled balloon were recorded. An anismus index was calculated. This expresses the increment of electrical activity on defecation straining over the resting value as a percentage of the increase on maximal voluntary contraction. The value is positive if the pressure on

TABLE II Outcome of biofeedback (BF) and muscular coordination training (MCT) given as the first treatment and as an alternative treatment after failure of the first

\begin{tabular}{|c|c|c|c|c|}
\hline & \multicolumn{2}{|c|}{ First treatments } & \multicolumn{2}{|l|}{ Cross overs } \\
\hline & $B F$ & $M C T$ & $B F \rightarrow M C T$ & $M C T \rightarrow B F$ \\
\hline No of patients & 26 & 25 & 3 & 5 \\
\hline Patient reported improvement & 18 & 16 & 2 & 2 \\
\hline \multicolumn{5}{|l|}{ Bowel frequency: } \\
\hline Increased & 13 & 12 & 1 & 4 \\
\hline Decreased & 10 & 12 & 1 & 1 \\
\hline Unchanged & 3 & 1 & 1 & 0 \\
\hline Total time spent straining decreased & 22 & 21 & 3 & 3 \\
\hline Decrease of EMG activity during straining & 22 & 20 & 2 & 3 \\
\hline
\end{tabular}

EMG = electromyographic. straining is greater than the resting pressure and negative if the straining pressure is less than the resting pressure. The normal value approximates to zero ${ }^{3}$ indicating that the anal pressure does not increase over the resting pressure on straining.

\section{Simulated defecation}

A lubricated balloon attached to a catheter was inserted into the rectum and inflated with 50 $\mathrm{ml}$ of water. The subject sat on a commode in privacy and was asked to expel the balloon. Success was recorded as passage of the balloon within five minutes.

The ability to expel a similar balloon containing $50 \mathrm{ml}$ of air was tested in the lateral position with the legs partially flexed. To maintain gentle constant initial traction and to detect descent of the pelvic floor, the catheter was attached to a spring balance and constant traction of $250 \mathrm{~g}$ was applied as the patient began to strain.

\section{MUSCULAR COORDINATION TRAINING}

All patients lay comfortably on their side with the hips and knees partly flexed. A lubricated balloon attached to a catheter was inserted into the lower rectum and inflated with $50 \mathrm{ml}$ of air. All patients were asked to contract the anal canal vigorously and note the sensation. They were also taught to direct propulsive force into the pelvis by taking a deep breath, contracting the upper abdominal (and diaphragmatic) muscles, and at the same time relaxing and protruding the lower abdomen. Correct performance of the manoeuvre was judged by visible protrusion of the lower abdomen. They were then asked to try and expel the balloon without developing any sense of contraction in the anal region while contracting the abdominal muscles as already practiced. Relaxation of the pelvic floor and effective abdominal straining were gauged by downward movement and then passage of the balloon. The movement of the intrarectal balloon was detected by the instructor through gentle traction on the catheter. Repeated instruction and when appropriate, encouragement and praise, were given.

The group using biofeedback were taught exactly as described above but, in addition, they watched the EMG trace on a monitor. A resting trace was first displayed and then 'frozen' on one channel of the screen. The wider amplitude of the trace on voluntary muscular contraction compared with the resting trace was next demonstrated using another channel. During balloon expulsion, the patient was taught to maintain a low amplitude of the trace recording muscular activity using the resting record constantly displayed as a model.

ETHICAL APPROVAL

The project was approved by the Ethical Committee of the City and Hackney Health Authority. 
TABLE III Symptoms recorded on diary cards before, at the end of treatment, and on follow up in the two treatment groups. Numbers shown represent numbers of patients or median (range)

\begin{tabular}{|c|c|c|c|c|c|c|}
\hline & \multicolumn{2}{|c|}{ Before treatment } & \multicolumn{2}{|c|}{ End of treatment } & \multicolumn{2}{|l|}{ Follow up } \\
\hline & $B F$ & $M C T$ & $B F$ & $M C T$ & $B F$ & $M C T$ \\
\hline $\begin{array}{l}\text { No } \\
\text { No straining episodes/wk } \\
\text { Time spent straining }(\mathrm{min} / \mathrm{wk}) \\
\text { Digitation } \\
\text { Pain duration }(\mathrm{min} / \mathrm{wk})\end{array}$ & $\begin{array}{l}31 \\
3(0-42) \\
12(0-1200) \\
18 \\
14(0-90)\end{array}$ & $\begin{array}{l}28 \\
5 \cdot 5(0-23) \\
15 \cdot 5(0-960) \\
12 \\
6(0-90)\end{array}$ & $\begin{array}{l}31 \\
3(0-7) \\
4(0-120) \\
9 \\
5(0-74)^{\star}\end{array}$ & $\begin{array}{l}28 \\
3(0-7) \\
4 \cdot 5(0-315)^{\star \star \star} \\
14 \\
1 \cdot 5(0-48)^{\star \star}\end{array}$ & $\begin{array}{l}31 \\
3(0-7) \\
4(0-360)^{\star \star} \\
13 \\
2(0-108)\end{array}$ & $\begin{array}{l}28 \\
2 \cdot 5(0-7) \\
2(0-230)^{\star \star \star} \\
15 \\
2(0-48)^{\star}\end{array}$ \\
\hline
\end{tabular}

Significance of differences from before treatment ${ }^{\star} p<0 \cdot 05,{ }^{\star \star} p<0 \cdot 02,{ }^{\star \star \star} p<0 \cdot 001$

$\mathrm{BF}=$ biofeedback, $\mathrm{MCT}=$ muscular coordination training.

POWER OF THE TRIAL AND STATISTICAL ANALYSIS

The total number of patients needed to show a difference in success rate of $30 \%$ from the previously established success rate ${ }^{1}$ of about $50 \%$ was regarded as a clinically significant difference. A series of 60 patients was judged to be necessary to show such a difference $(p<0.05)$ in success rate in three out of four trials. Differences between before and after treatment in each group were assessed as median and range by the one sample Wilcoxon signed rank test, or by Fisher's exact test.

\section{Results}

COMPARABILITY OF THE TREATMENT GROUPS Of 60 patients who entered the trial, one withdrew from the biofeedback (BF) group after one session and no follow up is available on that patient. Initial and follow up data are available for 29 patients treated first with $\mathrm{BF}$ and 30 treated with muscular coordination training (MCT) without a visual display; these 59 are regarded as the evaluable groups.

A comparison of the major symptoms and physiological parameters in the two treatment groups is shown in Table I: no major differences are apparent. The increased bowel frequency reported by 23 patients is explained

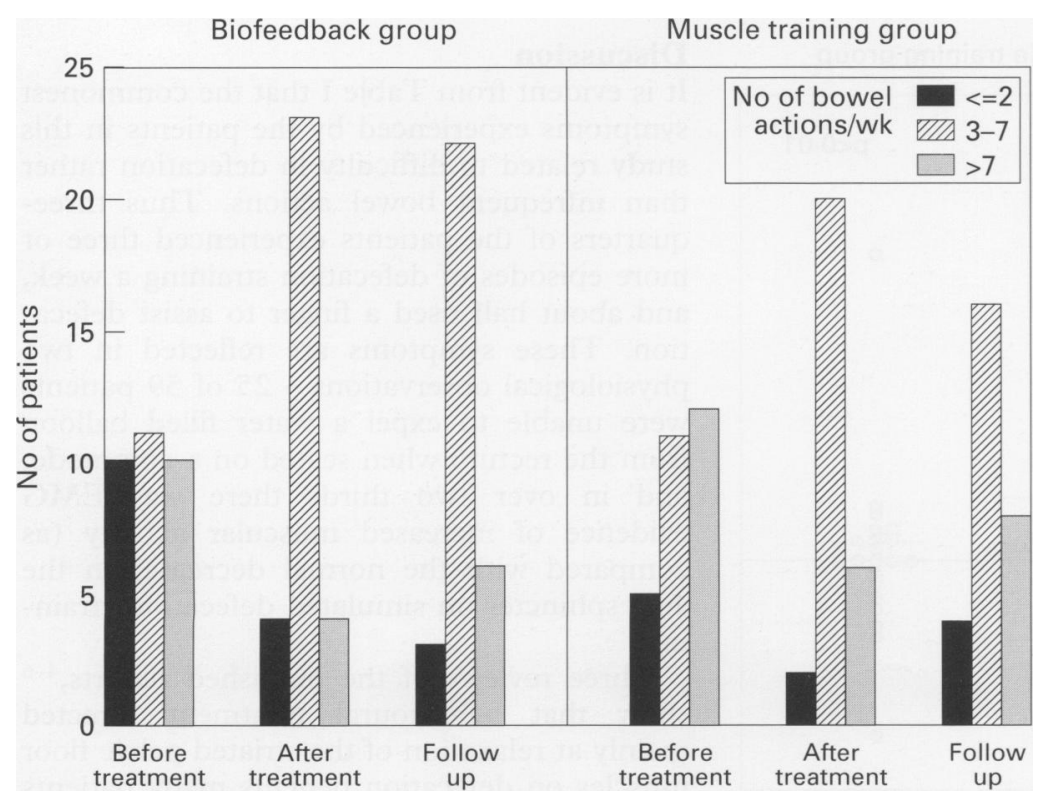

Figure 1: Weekly bowel frequency before and after treatment in the two treatment groups. Before treatment some patients experienced decreased frequency and others complained of increased frequency due to repeated straining efforts. After treatment the proportion of patients with a normal bowel frequency of 3-7 stools weekly increased similarly in both groups. by frequent straining efforts with the passage of small stools. Two patients in the BF group and one in the MCT group has a rectocele with barium trapping on defecating proctography. Difficulty in defecation, rather than infrequent stools, was the commonest problem reported by both groups.

\section{OUTCOME OF FIRST TREATMENT}

After two sessions neither the patient nor the instructor considered that any benefit had resulted for three patients receiving biofeedback and five patients who received training without biofeedback, these eight patients were then treated in the alternative manner. The results of treatment among the patients who received BF or MCT as the only treatment, and also the results of cross over treatments are shown in Table II. No difference in outcome between the two initial treatments is apparent. The small numbers in the cross over group are not sufficient for any conclusion, though no trend is apparent.

\section{OUTCOME AT END OF TREATMENT}

Full assessment was undertaken at the end of treatment. For 51 patients this was the initial mode of training, for eight patients it was at the end of the second treatment given after crossover. Overall, 14 of 31 patients in the Bf group regarded themselves as improved on seven consecutive days compared with 12 of 28 in the MCT group; one of 31 patients regarded their symptoms as unchanged or worse on each of 7 days in the BF group and eight of 28 in the MCT group $(\mathrm{p}<0.01)$, the remaining patients felt better on some days and unchanged or worse on others. Apart from this criterion, symptomatic results were similar (Table III).

Bowel frequency tended to increase among those with fewer than three bowel actions per week during the pretreatment period, and decrease in patients with more than seven bowel actions weekly as a result of a decreased number of straining episodes (Fig 1). As a result most patients reported a bowel frequency between three and seven weekly after treatment. Changes in bowel frequency before and after treatment were similar in both groups.

The number of straining episodes over seven days decreased to a similar extent in both groups as shown by a reduction in the number of patients with very frequent episodes as well as in the total time spent straining each week (Table III). Digitation was common in both 
TABLE IV Physiological measurements before and after treatment. Numbers shown represent numbers of patients or median (range)

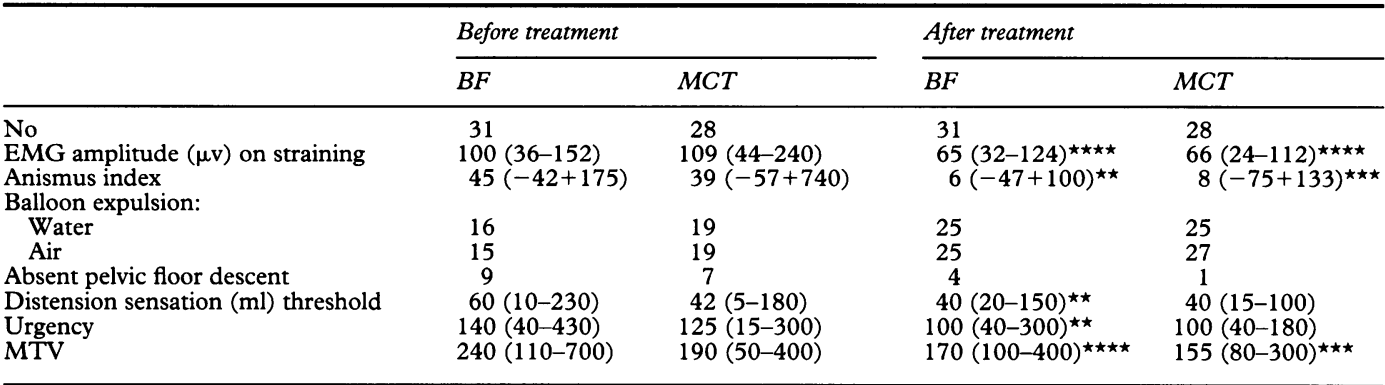

Significance between before and after treatment in each group $\left.{ }^{\star} \mathrm{p}<0.05,{ }^{\star \star} \mathrm{p}<0.02,{ }^{\star \star \star} \mathrm{p}<0 \cdot 01,{ }^{\star \star \star \star} \mathrm{p}<0 \cdot 001\right)$

$\mathrm{BF}=$ biofeedback; $\mathrm{MCT}=$ muscular coordination training; $\mathrm{EMG}=$ electromyographic; MTV=maximal tolerated volume.

groups but its occurrence at least once weekly did not alter with treatment. The duration of abdominal pain decreased similarly and significantly in both groups. There was little change in laxative consumption.

The anismus index improved similarly and significantly in both groups (Table IV and Fig 2). EMG activity of the external anal sphincter on defecation straining improved equally and significantly compared with pretreatment results in both groups (Table IV). The pelvic floor failed to descend on straining in nine patients in the BF group, and in seven patients in MCT group, before treatment but did descend in four and one of these patients respectively after treatment. There was also a trend towards increased ability to pass a water filled balloon in both groups (Table III). The volume of air in the rectal balloon necessary to elicit sensation decreased significantly at the end of treatment in the $\mathrm{BF}$ group (threshold median $60 v 42 \mathrm{ml}, \mathrm{p}<0.02$; urgency $140 v 100 \mathrm{ml}, \mathrm{p}<0.02$; maximal tolerated volume $240 v 170 \mathrm{ml}, \mathrm{p}<0.001)$. Changes in sensation were similar in the MCT group but were significant only for maximal tolerated volume. There was no

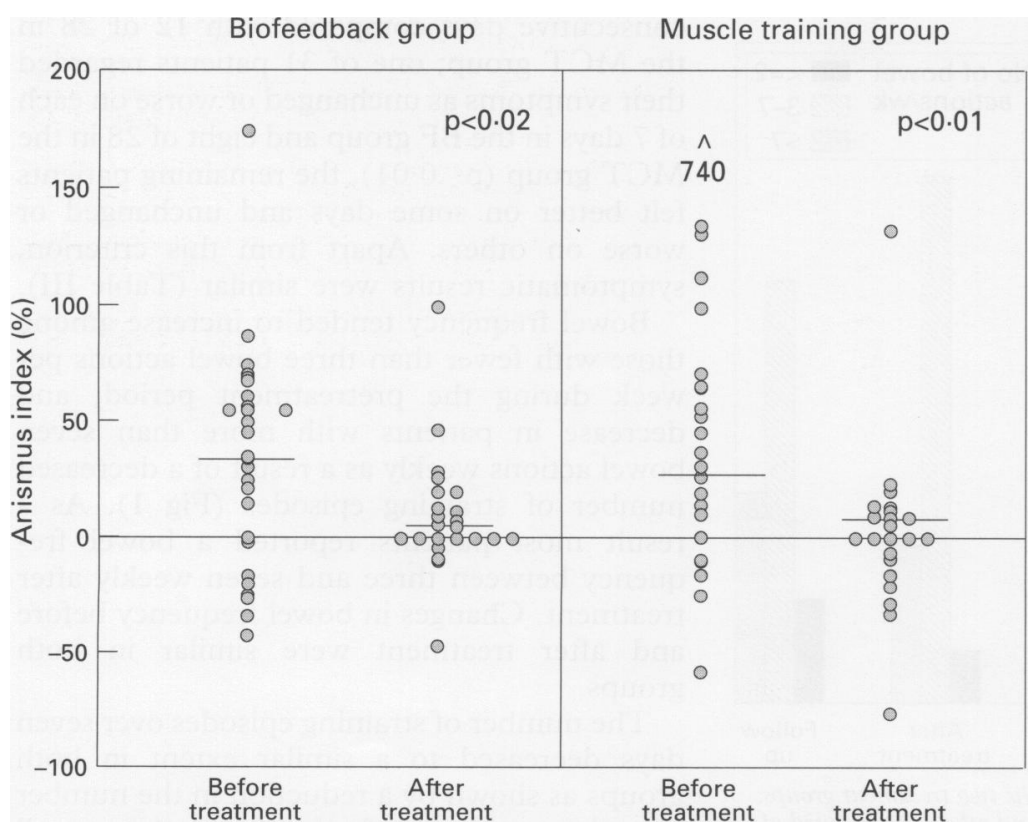

Figure 2: The anismus index before and after treatment in the two treatment groups. Normal values approximate to zero or a negative figure. (Points with similar values overlap.) consistent effect on measured intestinal transit rate, even among patients with slow transit initially.

NUMBER OF TRAINING SESSIONS

Training was considered adequate by patient and doctor after a mean of 3 (range 1-7) sessions in the BF group and $2(1-4)$ in the MCT group.

\section{FOLLOW UP}

The symptoms at the two follow up periods were so similar that only the results of the first diary card after completing treatment are shown in Table III. All patients returned one diary card during follow up but three patients in the BF group and two patients in the MCT group did not return their fourth and final card. There was little difference from the symptoms recorded at the end of treatment. Overall, 12 patients in each of the treatment groups described their symptoms as better on all seven days; seven patients in the BF group and five in the MCT group were unchanged or worse.

\section{Discussion}

It is evident from Table I that the commonest symptoms experienced by the patients in this study related to difficulty in defecation rather than infrequent bowel actions. Thus threequarters of the patients experienced three or more episodes of defecation straining a week, and about half used a finger to assist defecation. These symptoms are reflected in two physiological observations -25 of 59 patients were unable to expel a water filled balloon from the rectum when seated on a commode, and in over two thirds there was EMG evidence of increased muscular activity (as compared with the normal decrease) in the anal sphincter on simulated defecation straining.

Three reviews of the published reports, ${ }^{4-6}$ show that behavioural treatment directed mainly at relaxation of the striated pelvic floor muscles on defecation benefits many patients complaining of severe constipation. All previous studies, including our own previous study, ${ }^{1}$ have used some form of biofeedback technique in which the patients sees or hears, 
or both, a signal indicating external anal sphincter activity during defecation straining. Most of these studies have selected patients for treatment who contract, rather than relax, the pelvic floor muscles on straining. Physiological measurements by others ${ }^{3}$ have shown that, as in the results reported here, behavioural training succeeds in teaching such adults and children to relax the external anal sphincter during defecation straining. Isotopic proctography has shown that training increases the anorectal angle on straining and the defecation rate. ${ }^{3}$ We have confirmed the results of another study which showed that biofeedback reduces the volume needed to elicit a sense of distension in the rectum. ${ }^{3}$

In our previous study, ${ }^{1}$ about half of a consecutive unselected series of patients benefited from the method of biofeedback used for the patients in this trial and the results were similar here: in both groups about $40 \%$ of patients regarded their symptoms as improved on every day during two weeks of assessment. Furthermore, we observed that two types of muscular incoordination seem important. Firstly, some patients contract rather than relax the pelvic floor. Secondly, other patients seem unable to generate propulsive force in the pelvis, an observation confirmed by a study which showed that some patients fail to increase their intrarectal pressure normally on straining. ${ }^{8}$ This trial was designed solely to test whether or not the visual/auditory signal is an important component of the training technique. Our results show that training in abdominal muscle contraction with pelvic floor relaxation is equally effective with or without a measuring device to help the patient know whether or not the pelvic floor muscles relax. We cannot exclude the possibility that a few patients may benefit from such a device but training in muscular coordination alone can be the first treatment. This training requires assessment of the patient's muscular relaxation of the pelvic floor and contraction of the abdominal muscles by the instructor. The patient is constantly encouraged and praised for successful muscular control.

These findings are unlikely to be the result of a placebo effect. All the patients had been unsuccessfully treated with increased dietary fibre and drugs before entry to the study. We are not aware of any report of a significant placebo reduction in the need to strain at stool, increased bowel frequency in those in whom it was reduced, or altered physiological responses demonstrated by EMG of the pelvic floor muscles. Yoga, a non-specific form of relaxation did not improve the symptoms of five patients with severe defecation difficulties attributed to puborectalis dysfunction verified by EMG; only one of the five patients regained a normal EMG pattern of response. ${ }^{11}$ The sustained symptomatic benefit on follow up in this and other studies also argues against a placebo response. Nonetheless, a placebo controlled study of biofeedback in adult constipation is awaited. This study did not involve a placebo arm, the encouragement provided by the therapist served as a positive reinforcement to the patient learning abdomino-pelvic muscular coordination.

This treatment is harmless and long lasting. ${ }^{1679}$ Since our results suggest that it does not require the facilities of a physiological laboratory it could be used by clinical paramedical personnel. The treatment does require a good rapport between patient and instructor. Its mode of action may be more subtle than muscular retraining alone. ${ }^{10}$

The reason for an inability to strain effectively or relax the pelvic floor needs further assessment since psychological factors may be important in some patients.

DK was supported by the Alimentary Pharmacology and Therapeutics Trust and the British Digestive Foundation, MAK was supported by the St Mark's Research Foundation.

1 Koutsomanis D, Lennard-Jones JE, Kamm MA Prospective study of biofeedback treatment for patients with slow and normal transit constipation. Europ $\mathcal{J}$ Gastroenterol Hepatol 1994; 6: 131-7.

2 Evans RC, Kamm MA, Hinton JM, Lennard-Jones JE. The normal range and a simple diagram for recording whole gut transit time. Int $\mathcal{f}$ Colorect Dis 1992; 7: 15-7.

3 Papachrysostomou M, Smith AN. Effect of biofeedback on obstructive defecation - reconditioning of the defecation reflex? Gut 1994; 35: 252-6.

4 Enck $P$. Biofeedback training in disordered defecation: a critical review. Dig Dis Sci 1993; 38: 1953-60.

5 Bassotti G, Whitehead WE. Biofeedback as a treatment approach to gastrointestinal tract disorders. $A m \mathcal{J}$ approach to gastrointestinal
Gastroenterol 1994; 89: 158-64.

$6 \mathrm{Kamm} \mathrm{MA.} \mathrm{Motility} \mathrm{and} \mathrm{functional} \mathrm{diseases} \mathrm{of} \mathrm{the} \mathrm{large}$ intestine. Current opinion in Gastroenterology 1993; 9: 11-8.

7 Loening-Baucke V. Modulation of abnormal defecation dynamics by biofeedback treatment in chronically constipated children with encopresis. I Pediatr 1990; 116: 214-22.

8 Roberts JP, Thorpe AC, Williams NS. Assessment of defective rectal evacuation by dynamic integrated proctography. Br f Surg 1991; 78: 747.

9 Kawimbe BM, Papachrysostomou M, Binnie NR, Clare N, Smith AN. Outlet obstruction constipation (anismus) Smith AN. Outlet obstruction constipation (anis

10 Denis P. Biofeedback for constipation. In: Kamm MA Lennard-Jones JE. Constipation. Petersfield: Wrightson Liomedical, 1994: 349-53.

11 Dolk A, Holmstrom B, Johansson C, Frostell C, Nilsson BY. The effect of yoga on puborectalis paradox. Int $\mathcal{J}$ Colorect Dis 1991; 6: 139-42. 